\title{
Efecto del espesor de película y de la ubicación de la muestra en un secador solar directo, sobre la cinética de secado de ensilado de vísceras de tilapia roja (Oreochromis sp)
}

\author{
Jairo A. Camaño, Ana M. Rivera y José E. Zapata* \\ Facultad de Ciencias Farmacéuticas y Alimentarias, Grupo de Nutrición y Tecnología de Alimentos, Universidad de \\ Antioquia, Medellín, Colombia. (e-mail: edgar.zapata@udea.edu.co)
}

* Autor a quien debe ser dirigida la correspondencia.

Recibido Abr. 12, 2019; Aceptado Jun. 18, 2019; Versión final Ago. 17, 2019, Publicado Feb. 2020

\begin{abstract}
Resumen
Se evaluó el comportamiento en el secado de ensilado químico de vísceras de tilapia roja (Oreochromis sp), en función de la ubicación de la muestra dentro de un secador solar directo pasivo y del espesor de la película de la muestra. Se seleccionaron condiciones con base en criterios bromatológicos y microbiológicos, y parámetros cinéticos como el coeficiente de difusividad efectiva $\left(D_{\text {ef }}\right)$. Luego se modeló la cinética de secado, utilizando seis modelos empíricos y uno fenomenológico. Los resultados mostraron que muestras con un espesor de $2.40 \mathrm{~mm}$ y ubicadas en posiciones cerca de la salida de aire, tienen mejor comportamiento durante el secado garantizando un contenido de humedad del producto menor a $12 \%$, y entregando valores más altos de $D_{\text {ef. }}$ El modelo con el mejor ajuste fue el de Page, con más altos valores del coeficiente de correlación $\mathrm{R}^{2}$ y menores desviaciones comparado con los valores experimentales. Se concluye que la zona de ubicación del producto en el secador y el espesor de la película, afectan de manera significativa las características del producto obtenido.
\end{abstract}

Palabras clave: ensilaje químico; Oreochromis sp; secado solar directo; cinética de secado.

\section{Effect of film thickness and location of the sample inside a direct solar dryer on the drying kinetics of viscera silage of red tilapia}

\begin{abstract}
Drying behavior of chemical silage of red tilapia viscera (Oreochromis $s p$ ) was evaluated, in a direct solar dryer, as a function of the location of the sample inside the dryer and of the thickness of the film sample. The experimental conditions were selected according to bromatological and microbiological criteria and kinetic parameters such as the effective diffusivity coefficient $\left(D_{\text {ef }}\right)$. After that, the drying kinetics was modelled using six empirical models and one phenomenological model. The results showed that samples with $2.40 \mathrm{~mm}$ of thickness have better behavior during drying achieving moisture content of less than $12 \%$ in the dried product in zones closer to the air exit, which in turn gave higher $D_{\text {ef. }}$ The Page model provided the best fiiting of the data, with higher values of the correlation coefficient and lower deviations compared to experimental data. It is concluded that he location of the sample inside the dryer and the film thickness, significantly affect the characteristics of the product obtained.
\end{abstract}

Keywords: chemical silage; Oreochromis sp; direct solar drying; drying kinetics. 


\section{INTRODUCCIÓN}

La industria piscícola genera un elevado volumen de residuos, debido principalmente a que solo se consume entre el 30-40\% (w/w) del total de la producción (Martínez-Alvarez et al., 2015; Saadi et al., 2015; Minh, 2014). El $60-70 \%$ restante lo constituyen principalmente restos de fileteo (15-20\%), piel y aletas (1-3\%), huesos (9$15 \%)$, cabezas $(9-12 \%)$, vísceras $(12-18 \%$ ) y escamas $(5 \%)$, los cuales, a pesar de ser importantes fuentes de proteínas, muchas veces son descartados al ambiente generando fuertes impactos (Martínez-Alvarez, et al., 2015). Una de las alternativas de uso de los residuos piscícolas que cuenta con bajo costo de inversión y fácil implementación en cualquier escala, lo representa el ensilado (Van 't Land et al., 2017). Este proceso consiste en la licuefacción del pez completo o partes del mismo, por adicción de enzimas, bacterias ácido lácticas o ácidos ya sea orgánicos o inorgánicos, con el objetivos de provocar el descenso del pH (3.50-4.50), lo que estabiliza la mezcla al reducir la presencia de microorganismo putrefactivos, al mismo tiempo que favorece la autolisis de la masa por acción de las enzimas endógenas, con lo que se obtienen proteínas, péptidos pequeños y aminoácidos libres, entre otros nutrientes como ácidos grasos y minerales (Olsen et al., 2017). A pesar de que durante la licuefacción los aminoácidos son bastante estables, alguna degradación de lisina, metionina y particularmente triptófano, puede ocurrir (Gallardo et al., 2012). Sin embargo, diversos estudios han indicado que el EQ utilizado en la alimentación de peces (Goosen et al., 2016; Majumdar et al., 2014), camarones (Gallardo et al., 2012), pollos (Santana-Delgado et al., 2008) y cerdos (Nørgaard et al., 2012), no ha presentado efectos negativos sobre el desarrollo de los animales. En el caso de Noruega, 258150 toneladas de subproductos tanto de pesca de captura como de piscicultura, fueron procesadas en 2014 por medio de ensilaje (Richardsen, et al., 2015).

Usualmente el ensilado es elaborado y almacenado como líquido sellado, hasta el momento de su uso (Goddard y Perret, 2005), en cuyo caso puede ser incluido directamente en dietas húmedas, pero su uso en dietas secas presenta algunos inconvenientes, debido a su alto contenido de agua (Madage et al.,2015). Por lo cual se han evaluado procesos de secado mezclándolo con otros ingredientes como soya, plumas, subproductos avícolas o salvado de cereales (Olsen et al., 2017); (Madage et al., 2015). Al secar el producto se incrementa la concentración de los ácidos orgánicos adicionados al principio del proceso, lo cual es deseable porque se ha encontrado que ácidos orgánicos de cadena corta, como el propiónico y el fórmico, mejoran el crecimiento y desempeño de animales de granja, y posiblemente peces y crustáceos (Olsen et al., 2017) (Martínez-Alvarez et al., 2015). Además, el secado reduce los costos de transporte y almacenamiento (Goddard y Perret, 2005) e incrementa la concentración de proteínas de los ensilados, la cual de por sí ya era de interés en la forma húmeda. Todos estos aspectos han hecho que el secado incremente el valor del ensilado como materia prima para alimentación animal (Madage et al., 2015).

Para secar ensilados se han utilizado tambores rotatorios, hornos, co-secado, como métodos convencionales, mientras que también se ha evaluado el secado solar, en el que se cuenta el secado al exterior, en gabinetes o en politunel de polietileno (Goddard y Perret, 2005). En los procesos convencionales de secado, se utiliza energía proveniente de combustibles fósiles, lo cual es generalmente costosa e impactante del ambiente, mientras que el secado solar requiere tiempos prolongados, con exposición del material a la contaminación microbiológica, principalmente cuando se hace al exterior (Goddard y Perret, 2005). Por otro lado, se ha encontrado que en los secadores solares el secado no es homogéneo, y puede existir diferencias entre el producto ubicado en diferentes zonas dentro del secador. En el presente trabajo se propone evaluar el comportamiento que tiene el secado de EQ de vísceras de tilapia roja (Oreochromis sp), en un secador solar directo pasivo, en función de la zona dentro del secador y el espesor de la película de ensilado que se utilice. Se modela la cinética de secado con diferentes modelos y se hace la caracterización microbiológica y bromatológica del producto seco obtenido.

\section{METODOLOGÍA}

La metodología presenta varias subsecciones. Inicialmente se describe la obtención y preparación del EQ, seguido por la descripción de los secadores solares y el proceso de secado solar, después se establece la metodología para el análisis del EXP1 y EXP2, toma de datos, métodos analíticos, cinética de secado y estimación de parámetros termo-físicos, modelamiento del proceso con la bondad de ajuste, y por último se establece el análisis estadístico.

\section{Manejo de material}

Las vísceras de tilapia roja (Oreochromis $s p$ ) fueron suministradas por un productor comercial, en San Jerónimo - Colombia $\left(6^{\circ} 27^{\prime} 45.0^{\prime \prime} \mathrm{N} 75^{\circ} 46^{\prime} 43.2^{\prime \prime W}\right)$, se transportaron en condiciones de refrigeración hasta las instalaciones del laboratorio, donde posteriormente se sometieron a un proceso térmico a $67^{\circ} \mathrm{C}$ por 30 minutos y se almacenaron por un periodo de 12 horas a $-20^{\circ} \mathrm{C}$ y luego separar la grasa por decantación para el posterior ensilaje. 


\section{Ensilaje químico de vísceras de Tilapia roja}

Para la obtención del EQ, las vísceras previamente desengrasadas se trituraron utilizando un procesador de alimentos (Black y Decker, USA), con el fin de homogeneizar el material para el posterior ensilaje. Estas vísceras se almacenaron en contenedores plásticos de polietileno en los cuales se adiciono $1.16 \%$ de ácido fórmico, $0.03 \%$ de ácido sulfúrico, $0.12 \%$ de sorbato de potasio (conservante) y $0.002 \%$ de butil hidroxitolueno (antioxidante). Posteriormente, se almacenaron herméticamente a temperatura ambiente $\left(25^{\circ} \mathrm{C}\right)$ por un periodo de 10 días hasta $\mathrm{pH} \leq 4$.

\section{Secador solar}

Se utilizaron dos secadores solares directos (colectores), en un modo pasivo (convección natural), en el cual se convierte la energía solar en energía térmica. Cada secador solar consta de una placa con dimensiones de $1.48 \mathrm{~m}$ de largo, $0.63 \mathrm{~m}$ de ancho y $0.12 \mathrm{~m}$ de altura, para conformar una cámara útil de secado de 0.1118 $\mathrm{m}^{3}$ con dos componentes: 1) Una placa metálica de acero inoxidable pintada de color negro en la parte expuesta al sol para absorber energía solar térmica; 2) una cubierta transparente de polimetilmetacrilato (PMMA) de $4 \times 10^{-3} \mathrm{~m}$ de espesor y transmisividad entre el 80 y $90 \%$, para permitir la entrada de la radiación solar. En ambos secadores se colocó por debajo de la placa metálica una capa de $0.003 \mathrm{~m}$ de espesor de fibra de vidrio, y todos los componentes se ensamblaron con unas tiras de caucho sintético de $0.003 \mathrm{~m}$ de espesor adheridas a la superficie de contacto o cierre entre la placa negra y la cubierta transparente que minimiza la pérdida de calor. Los colectores tenían dos aberturas rectangulares de $0.095 \mathrm{~m}$ de altura y 0.08 $\mathrm{m}$ de ancho en cada extremo para la circulación del aire por convección natural, como se muestra en la figura 1. La radiación solar ingresa en el interior de la cámara a través de la cubierta transparente de PMMA en donde es absorbida por la superficie negra transmitiendo esa energía al aire que circula por convección natural (Sharma, Chen, y Vu Lan, 2009). Por su parte, el aire fluye desde la entrada a través de la abertura ubicada en la zona inferior como se indica en la figura 1 , una vez entra el aire se calienta y fluye a través de la cámara y el producto, el cual se encuentra en cajas de Petri en películas de diferente espesor. Al final, el aire húmedo se dirige a la abertura de salida arrastrando consigo el agua extraída del producto (Badaoui et al., 2019).

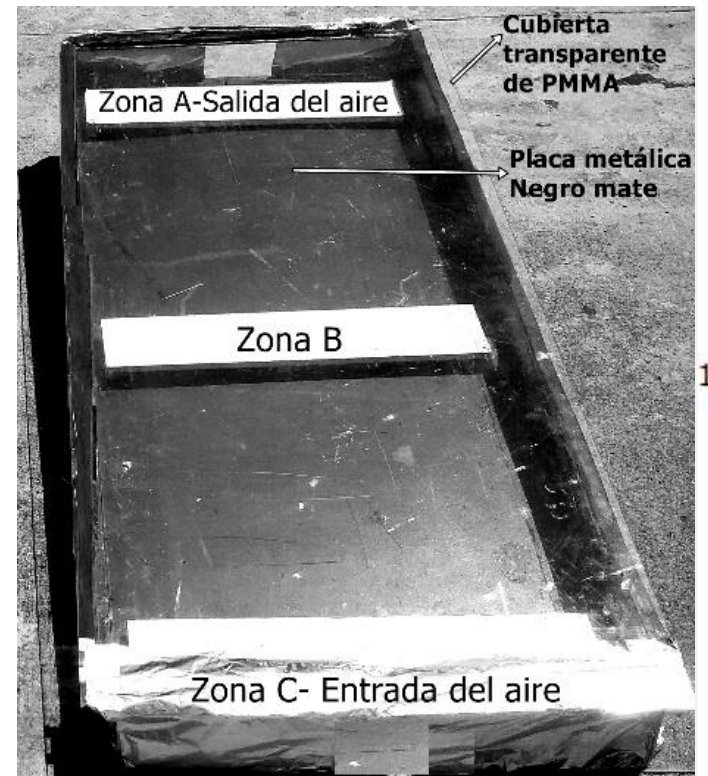

(A)

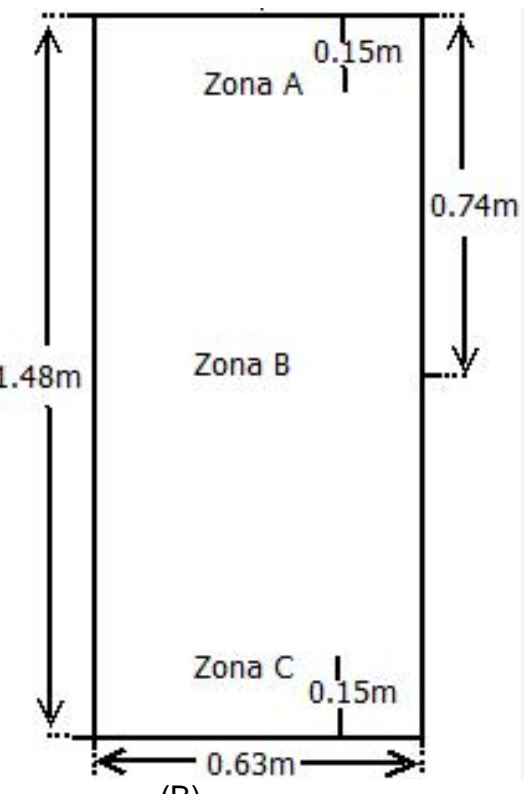

(B)

Fig. 1: Diagrama general del secador solar directo. (A) Diagrama esquemático de los componentes del sistema de secado. (B) Vista en planta con conformación geométrica del secador solar.

\section{Proceso de secado solar}

Los experimentos fueron llevados a cabos durante el mes de octubre y noviembre del 2018, en la ciudad de Medellín-Antioquia, cuyas coordenadas geográficas son $6^{\circ} 13^{\prime} 55^{\prime \prime} \mathrm{N} 75^{\circ} 34^{\prime} 05^{\prime \prime} \mathrm{O}$ y 1475 metros sobre el nivel del mar. Los colectores solares fueron orientados hacia el nordeste basado en las estadísticas de las direcciones del viento en la ciudad de Medellín con un ángulo de inclinación de $6^{\circ}$ con respecto al horizontal, igual a la latitud del lugar, de forma que el aire lograra entrar de manera directa por el orifico en el extremo (Fig.1). Los experimentos iniciaron a las 8:30 am, hora en la cual el sol empieza a mostrar sus condiciones para el secado, mientras que la duración de la operación estuvo condicionada por el momento en el que se detuvo la pérdida de peso de las muestras de EQ. 


\section{Evaluación del efecto de la zona y del espesor de película sobre el secado (EXP1).}

Se utilizaron dos colectores, los cuales se sectorizaron en 3 zonas para evaluar el efecto que cada zona ejerce sobre el proceso de deshidratación solar. La zona A se ubicó $0.15 \mathrm{~m}$ antes de la abertura de salida del aire en el colector (parte superior), la zona B en la mitad del colector correspondiente a $0.74 \mathrm{~m}$ desde los extremos verticales y la zona $C$ se ubicó a $0.15 \mathrm{~m}$ después de la abertura de entrada del aire (parte inferior) como se muestra en la figura 2A. En cada zona se situaron 4 cajas de Petri con dimensiones de $0.10 \mathrm{~m}$ de diámetro y $0.01 \mathrm{~m}$ de altura utilizadas como cama de secado. Para evaluar el efecto del espesor de película de EQ, se utilizaron capas de $1.20 \times 10^{-3} \mathrm{~m}$ y $2.40 \times 10^{-3} \mathrm{~m}$ de espesor para el colector $X(\mathrm{CX})$ y colector $\mathrm{Y}(\mathrm{CY})$, respectivamente, teniendo en cuenta que la única variable modificada en los colectores fue el espesor de película de EQ garantizando que las demás condiciones sean identificas. Las mediciones de las condiciones externas se realizaron por medio de un dataloger de temperatura y humedad CEM DT-171 (Metershack, Sudáfrica), este fue localizado en el ambiente, el cual consta de un termómetro integrado con un higrómetro con resolución $0.1 \%$ Humedad relativa $(\mathrm{HR})$ y ${ }^{\circ} \mathrm{C}$. Al ensilado seco (ES) se le realizaron mediciones bromatológicas y microbiológicas, además se construyeron curvas características de secado y se determinó el $D_{\text {ef, }}$ con el fin de establecer las zonas con mejor comportamiento en el secado.

\section{Modelamiento de la cinética de secado EXP2}

Se usó el colector CY $\left(2.40 \times 10^{-3} \mathrm{~m}\right.$ de espesor de película) para caracterizar la cinética y modelar el secado de las zonas seleccionadas a partir del EXP1 (zonas A y B). La ubicación y sectorización de las zonas y las cajas de Petri, siguieron los mismos lineamientos del EXP1. Para la medición de las condiciones del aire se ubicaron tres dataloger de temperatura y humedad CEM DT-171 (Metershack, Sudáfrica) a lo largo del eje longitudinal dentro del colector $\mathrm{CY}$ y uno en el ambiente. El primero en la entrada del aire (zona C), el segundo en la mitad (zona B), el tercero en la salida del aire (zona A). Esta configuración experimental se ilustra en la figura $2 \mathrm{~B}$.

\section{Toma de datos durante el secado}

En los dos experimentos se siguió la evolución del proceso de secado solar, para ello las muestras de EQ fueron pesadas en 7 tiempos, la inicial, las siguientes cuatro mediciones cada $0.5 \mathrm{~h}$ y las dos últimas cada hora, para un tiempo total de secado de $4 \mathrm{~h}$. Se usó una balanza analítica txb2201L (Shimadzu, Japón) con precisión de $0.01 \mathrm{~g}$. La luminosidad solar se midió cada $0.083 \mathrm{~h}$ durante todo el tiempo de secado, para lo que se utilizó un luxómetro LX-105 (Lutron electronic, Taiwan) y se utilizó un factor de conversión para el cambio de LUX a W/m² considerándose como radiación solar. El seguimiento de la temperatura y HR del aire en el ambiente y en los diferentes puntos dentro del secador, se llevó a cabo cada $0.083 \mathrm{~h}$ con dataloger de temperatura y humedad CEM DT-171 (Metershack, Sudáfrica) con memoria de datos y transferencia a un ordenador mediante USB, por medio del software dataloger grpah.

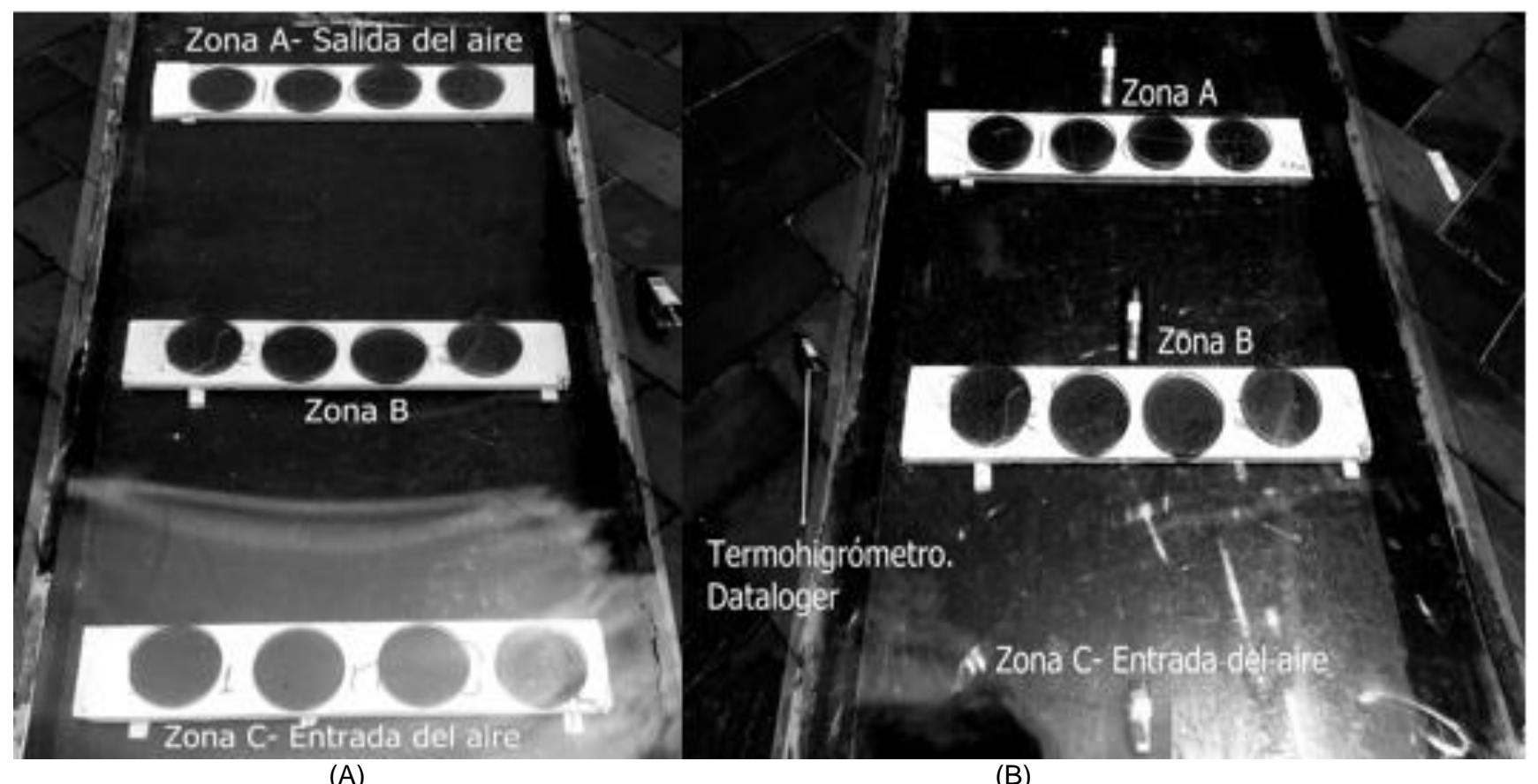

(A)

Fig. 2: Vista en planta de la configuración experimental para el secado solar del EQ. A) EXP1 con colector CX y CY. B) EXP2 con colector CY y termohigrómetros en las diferentes zonas. 


\section{Métodos analíticos}

Se realizaron análisis fisicoquímicos a la muestra de ensilado fresco (EF) y a las muestras de ES del EXP1, siguiendo los métodos establecido por la AOAC (AOAC, 2000), todos los análisis fueron determinados por triplicado. La Humedad fue determinada en estufa de aire (Thermo Scientific ${ }^{\mathrm{TM}}$, USA). El contenido de proteína por el método de Kjeldahl (Velp scientifica, Italia). El extracto etéreo o grasa fue estimado usando un montaje Soxhlet (Radleys,USA). Las cenizas fueron analizadas por incineración en mufla (Terrigeno, Colombia). Por otro lado, para los análisis microbiológicos se tomaron muestras con un porcentaje de humedad entre el 10\% $-12 \%$. El análisis de mesófilos aerobios, mohos y levaduras, fueron realizados empleando el agar Plate count (OXOID LTD, Inglaterra) y agar OGYE base según ISO (Merck KGaA, Alemania), respectivamente. El número más probable (NMP) de coliformes totales y fecales fue determinado utilizando el agar VRBA (Merck, Alemania). Finalmente, todos los resultados obtenidos se contrastaron conforme la norma técnica Colombiana (NTC) 2107 de 1999.

\section{Cinética de secado y estimación de parámetros termo-físicos}

En ambos experimentos (EXP1 y EXP2), la evolución del proceso de secado del EQ en los colectores solares CX y CY se representó mediante dos curvas: El porcentaje de humedad (MT) en función del tiempo y la velocidad de secado (VS) en función de la humedad. Estas curvas se elaboraron para cada experimento en forma separada, para lo cual MT se calculó con la ecuación 1, donde MH es la masa de EQ en el momento t, $M D$ corresponde a la masa de la materia seca de la muestra de $E Q$, esta se calculó con base al porcentaje de materia seca determinado gravimétricamente a $105^{\circ} \mathrm{C}$ en estufa de aire Heratherm (Thermo Scientific, España) (Karthikeyan y Murugavelh, 2018). La velocidad de secado se determinó mediante el cálculo directo del incremento del contenido de humedad con respecto al tiempo, como se muestra en la ecuación 2 (Badaoui et al., 2019). Previamente la variación de la masa MH, fue medida a intervalos de tiempo, de forma que se obtuvieran datos de MT en función del tiempo.

$$
\begin{aligned}
& M T=\frac{(M H-M D)}{M H} * 100 \\
& V S=\frac{\Delta M T}{t}
\end{aligned}
$$

La relación de humedad (MR) se estimó con la ecuación 3, donde Mo hace referencia a la humedad en el inicio del experimento y Me es la humedad en equilibrio.

$$
M R=\frac{M T-M e}{M o-M e}
$$

\section{Modelo fenomenológico}

Para EXP1 y EXP 2 se determinó el $D_{\text {ef }}$ del agua desde el interior de la película de EQ hasta la superficie, se aplicó un modelo fenomenológico basado en la segunda ley de Fick para la difusión en estado no estacionario, suponiendo la concentración en la interface constante, flujo de transferencia de masa unidireccional y netamente difusional, así como la película de EQ una placa plana de longitud infinita. El modelo resultante es el que se muestra en la ecuación 4 (Crank., 1975). Para la solución analítica, la ecuación fue truncada al décimo término de la serie $(n=10)$ y se utilizaron 7 datos de MR obtenidos en las respectivas curvas de secado de cada zona y colector.

$$
M R=\frac{8}{\pi^{2}(2 n+1)^{2}} \sum_{n=0}^{\infty} \exp \left[-D_{e f}(2 n+1)^{2} \frac{\pi^{2}}{4 l^{2}} t\right]
$$

El comportamiento de MR en función del tiempo, de las películas de EQ en el EXP2, se ajustó a 6 modelos matemáticos de secado de capa delgada, los cuales se muestran en la Tabla 1. (Essalhi et al., 2018). El ajuste se hizo usando el método de mínimos cuadrados, con el software "Mathlab" (Licencia 914762, versión 2018).

\section{Bondad de ajuste}

Para determinar el modelo apropiado para la descripción de la cinética de secado de $E Q$, se seleccionaron los siguientes criterios: 1) coeficiente de correlación $\left(R^{2}\right)$; 2) chi-cuadrado reducido $\left(X^{2}\right)$; 3 ) error medio absoluto (MAE); 4) error cuadrático medio (RMSE). 
Tabla 1: Ecuaciones semi-teóricas y empíricas del secado de capa delgada

\begin{tabular}{|c|l|l|l|}
\hline $\mathrm{N}^{\circ}$ del modelo & \multicolumn{1}{|c|}{ Nombre } & Ecuación & \multicolumn{1}{|c|}{ Referencias } \\
\hline 1 & Page & $\mathrm{MR}=\exp \left(-\mathrm{kt}^{\mathrm{n}}\right)$ & (Zhand y Litchfield, 1991) \\
\hline 2 & Midilli & $\mathrm{MR}=\mathrm{aexp}\left(-\mathrm{kt}^{\mathrm{n}}\right)+\mathrm{b} \mathrm{t}$ & $($ Essalhi et al., 2018) \\
\hline 3 & Danish & $\mathrm{MR}=\exp \left(-\mathrm{kt}^{\mathrm{n}}\right)+\mathrm{b}$ & $($ Danish et al., 2016) \\
\hline 4 & Logaritmica & $\mathrm{MR}=\mathrm{aexp}(-\mathrm{kt})+\mathrm{c}$ & $($ Essalhi et al., 2018) \\
\hline 5 & $\begin{array}{l}\text { Henderson y } \\
\text { pabis }\end{array}$ & $\mathrm{MR}=\mathbf{a e x p}(-\mathbf{k t})$ & $($ Essalhi et al., 2018) \\
\hline 6 & Verma & $\mathrm{MR}=\mathrm{aexp}(-\mathrm{kt})+(1-\mathrm{a}) \exp (-\mathrm{gt})$ & $($ Essalhi et al., 2018) \\
\hline
\end{tabular}

\section{Análisis estadístico}

Las mediciones de las variables fisicoquímicas del proceso se llevaron a cabo por triplicado y los resultados obtenidos se presentaron como la media \pm desviación estándar. Se aplicó una prueba de comparaciones múltiples con metodología mínima diferencia significativa (LSD) y a: 0.05 para determinar las diferencias estadísticamente significativa entre las mediciones bromatológicas entre las zonas del EXP1.

\section{RESULTADOS Y DISCUSIÓN}

Los resultados se muestran en dos secciones: en una se muestran los resultados obtenidos del EXP1, en donde se seleccionaron las mejores condiciones y configuraciones para el secado; y en otra sección, EXP2 en donde se aplicó modelación empírica y fenomenológica.

\section{Evaluación del efecto de la zona y del espesor de película sobre el secado (EXP1).}

Con los resultados de esta sección experimental se establecen las condiciones del ES, además se seleccionan las zonas en el secador y el espesor de la película para hacer el modelamiento del proceso de secado.

\section{Caracterización bromatológica}

En la tabla 2 se presentan los resultados del análisis bromatológico de las muestras provenientes del EXP1, para el colector CX $\left(1.20 \times 10^{-3} \mathrm{~m}\right)$ y el colector $\mathrm{CY}\left(2.40 \times 10^{-3} \mathrm{~m}\right)$ para un tiempo de secado de 4 horas, en la cual las diferentes letras en la misma columna indican diferencias significativas entre los valores $(p<0.05)$ por la prueba de comparaciones múltiples por metodología LSD. Se observa que el espesor de película y la ubicación en el colector generan diferencias estadísticamente significativas sobre las características del ES. En el caso de la humedad estas diferencias son mayores entre la zona $\mathrm{C}$ y las otras dos zonas, para los dos espesores de película evaluados (colector $\mathrm{CX}$ y $\mathrm{CY}$ ). Esto es debido a que en estas dos zonas (A y B) el aire ha tenido el recorrido suficiente dentro del colector para alcanzar la temperatura y HR necesaria para poner en marcha los tres mecanismos de transferencia de calor que pueden darse en un colector solar (Hamdi et al., 2018). A pesar que el colector $C X\left(1.20 \times 10^{-3} \mathrm{~m}\right)$ obtiene valores de humedad final más bajas que el colector CY $\left(2.40 \times 10^{-3} \mathrm{~m}\right)$, se debe tener en cuenta que los valores de humedad obtenidos en $\mathrm{CY}$, son suficientes para estabilizar el producto ya que se garantiza humedades menores al $12 \%$ en las zonas $A$ y $B$ (Goddard y Perret, 2005), considerando que la masa de producto procesado en CY es el doble que la de CX y las condiciones de humedad y temperatura del aire en los dos colectores son distintas.

Las características de los ES que se presentan en la tabla 2, ponen de manifiesto el potencial que este sustrato tiene como fuente de proteína para la alimentación animal puesto que posee los niveles de proteína y lípidos requeridos por camarones (Rodríguez-Gonzáles et al., 2018) y por algunos peces juveniles carnívoros, en donde se ha demostrado que el uso de dietas con estas características proporcionan un aumento en el crecimiento debido a los aminoácidos y contribuyen a una fuente de energía importante de ácidos grasos esenciales, así como un vehículo de vitaminas liposolubles (Sagada et al., 2017). A su vez, otros estudios han mostrado que el uso de EQ secado al sol mezclado con otros ingredientes se puede usar como sustituto de harina de pescado por su valor nutricional en alimentos para especies omnívoras (Goddard y Perret, 2005). Esto corresponde a un aporte significativo en la industria acuícola, puesto que uno de los principales inconvenientes que se presenta son los elevados costos en la producción de piensos para garantizar el contenido dietario de proteína, mientras con el ES se pueden lograr estos niveles a costos más bajos aprovechando residuos de la industria piscícola. 
Tabla 2: Caracterización bromatológica de muestras de ensilado (\% Base seca).

\begin{tabular}{|l|c|c|c|c|c|}
\hline \multirow{2}{*}{\begin{tabular}{l} 
Colector \\
\cline { 2 - 5 }
\end{tabular}} & Muestra & Humedad & Proteína & Grasa & Ceniza \\
\cline { 2 - 6 } $\begin{array}{l}\text { CX:1.20 } \times 10^{-3} \mathrm{~m} \text { de } \\
\text { espesor }\end{array}$ & ES Zona A & $6.012 \pm 0,48^{\mathrm{b}}$ & $40.507 \pm 1.08^{\mathrm{b}}$ & $21.565 \pm 2.90^{\mathrm{b}}$ & $5.891 \pm 0.86^{\mathrm{b}}$ \\
\cline { 2 - 6 } & ES Zona B & $5.209 \pm 0.78^{\mathrm{b}}$ & $41.181 \pm 0.1^{\mathrm{c}}$ & $23.274 \pm 0.75^{\mathrm{c}}$ & $6.287 \pm 0.89^{\mathrm{b}}$ \\
\cline { 2 - 6 } & ES Zona C & $12.444 \pm 0.03^{\mathrm{c}}$ & $34.983 \pm 0.06^{\mathrm{c}}$ & $20.662 \pm 4.02^{\mathrm{d}}$ & $5.804 \pm 3.9^{\mathrm{c}}$ \\
\hline \multirow{2}{*}{$\begin{array}{l}\text { CY: } 2.40 \times 10^{-3} \mathrm{~m} \text { de } \\
\text { espesor }\end{array}$} & ES Zona A & $11.054 \pm 0.03^{\mathrm{c}}$ & $39.372 \pm 0.03^{\mathrm{b}}$ & $21.460 \pm 0,69^{\mathrm{b}}$ & $5.809 \pm 0.49^{\mathrm{c}}$ \\
\cline { 2 - 6 } & ES Zona B & $11.038 \pm 0.04^{\mathrm{c}}$ & $40.709 \pm 0,71^{\mathrm{c}}$ & $21.439 \pm 1.07^{\mathrm{b}}$ & $5.777 \pm 0.59^{\mathrm{c}}$ \\
\cline { 2 - 6 } & ES Zona C & $18.446 \pm 0.61^{\mathrm{d}}$ & $35.914 \pm 0.66^{\mathrm{d}}$ & $19.984 \pm 0.23^{\mathrm{d}}$ & $5.516 \pm 0.27^{\mathrm{c}}$ \\
\hline
\end{tabular}

\section{Caracterización microbiológica}

Se obtuvieron muestras de ES de las zonas A y B en los colectores CX y CY del EXP1, para los análisis microbiológicos, debido a que fueron las que alcanzaron humedades menores al $12 \%$. En tabla 3 se observa que el crecimiento de microorganismo de las muestras está conforme con los parámetros establecidos por la NTC 2107. Por otro lado, el análisis corrobora que la poca actividad acuosa permite evitar el deterioro del alimento, ya que los microorganismos requieren agua en niveles superiores del $12 \%$ para soportar el crecimiento de bacterias, mohos y levaduras (Goddard y Perret, 2005).

Tabla 3: Caracterización microbiológica

\begin{tabular}{|l|l|l|}
\hline Prueba & Resultado (UFC/g) & Referencia (UFC/g) \\
\hline Coliformes totales y fecales & Ausencia & $10 \times 10^{4}$ \\
\hline Mohos y levaduras & $2.00 \times 10^{3}$ & $10 \times 10^{4}$ \\
\hline Mesófilos aerobios & $3.90 \times 10^{5}$ & $10 \times 10^{5}$ \\
\hline
\end{tabular}

Variación de las condiciones externas durante el periodo de secado

Las condiciones externas en el EXP1 se registraron desde las 8:30 am hasta las 12:30 pm como se observa en la figura 3, comprendiendo un tiempo de 4 horas para el proceso. Durante el tiempo del ensayo, la radiación solar presenta un leve incremento, lo cual a su vez con lleva a un aumento en temperatura y descenso en la HR. La radiación oscilo entre 345 y $910 \mathrm{~W} / \mathrm{m}^{2}$, con valores mayores a los reportados en un estudio de secado solar de manzanilla (Baher et al., 2018), y similares a los de obtenidos en el secado solar de cúrcuma (Karthikeyan y Murugavelh, 2018) y secado solar de uvas (Hamdi et al., 2018).

Los valores máximos se registraron al mediodía y los mínimos 2 horas después de iniciar el experimento. La temperatura ambiente oscilo entre 31 y $46{ }^{\circ} \mathrm{C}$, mientras que la HR fluctuó entre 15.10 y $29.50 \%$.

\section{Efecto del espesor de película de EQ en el secado}

En la figura 4 se muestra el comportamiento de MT en función del tiempo, para los colectores $\mathrm{CX}$ y $\mathrm{CY}$, los cuales contienen EQ en películas de $1.20 \times 10^{-3} \mathrm{~m}$ y $2.40 \times 10^{-3} \mathrm{~m}$, respectivamente. A pesar de que es evidente que las películas con $1.20 \times 10^{-3} \mathrm{~m}$ (Fig. 4A), se deshidratan hasta valores inferiores que las de $2.40 \times 10^{-3} \mathrm{~m}$ (Fig. 4B), ambos espesores presentaron resultados favorables al secado, con comportamientos típicos de los sistemas que utilizan aire caliente, una fase inicial de adaptación del material a las condiciones del aire, seguida por una fase de descenso rápido y finamente por una de estabilidad de MT (Hincapié y Zapata, 2019). La primera fase puede deberse a la alta solubilidad de los solutos presentes (Gabas et al., 2009) y a la complejidad de su microestructura, que dificulta el intercambio de fluidos entre el interior y exterior de la capa de producto (Puente et al., 2011). En esta fase, además, la masa de producto debe incrementar su temperatura para favorecer el paso de las moléculas de agua desde el líquido al vapor. Por tal razón, dicha fase tiene una duración mayor en el colector $\mathrm{CY}$, porque la masa de producto a calentar en este colector es mayor. La segunda fase de secado corresponde a la etapa en la que el producto ha incrementado su temperatura y se encuentra en la superficie lista para cambiar de fase, por esta causa el proceso de secado se desarrolla con mayor rapidez que en la primera fase y de forma constante. La última fase empieza cuando la mayor parte del agua del producto ha salido y existen una concentración de solidos que retienen el agua que aún permanece, además de que la superficie seca en el producto forma una barrera a la transferencia de masa y calor, lo que produce un estado en el que la salida de agua es lenta y el sistema se va acercando al equilibrio (Qiu et al. 2018). 


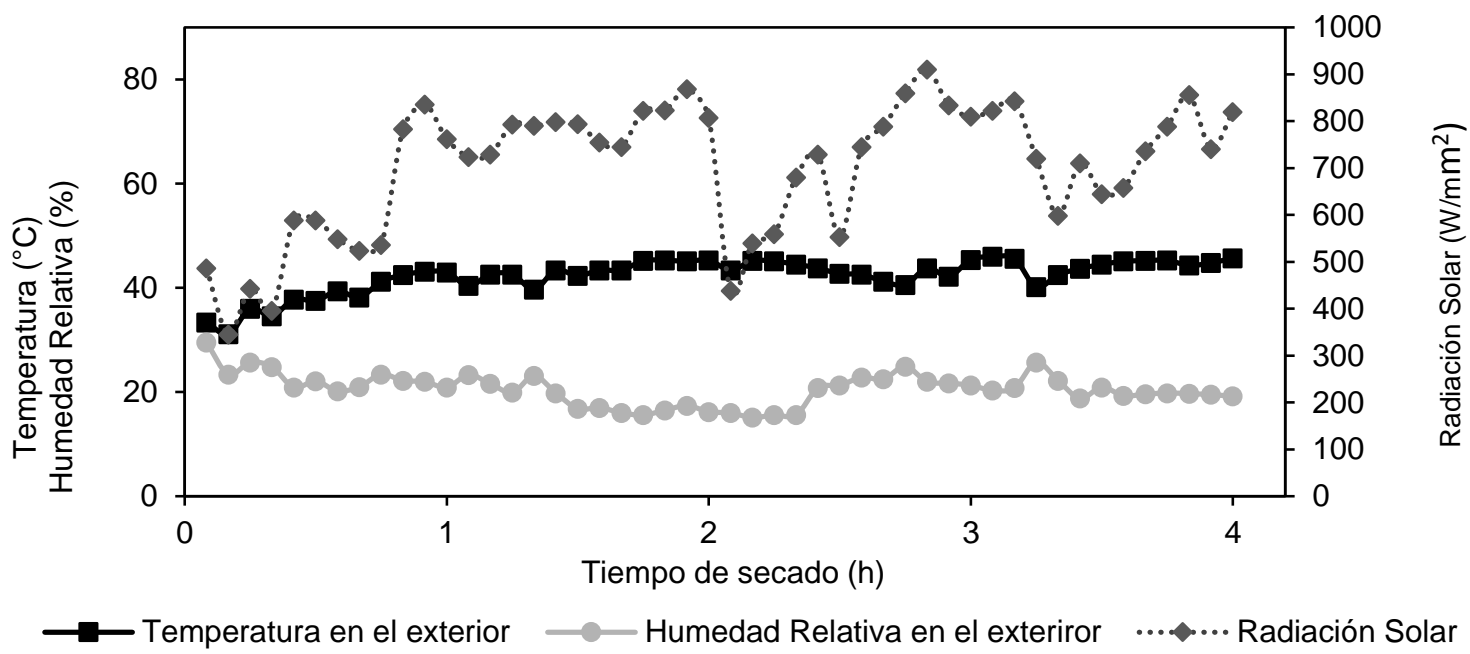

Fig. 3: Variación de las condiciones climaticas en el EXP1. Radición solar frente a temperatura y humedad relativa, durante el tiempo de secado.

En ambos espesores las zonas que mayor deshidratación presentan son la zonas A y B (tabla 2), debido a que el aire ha permanecido mayor tiempo dentro de la cámara y por tal razón ha incrementado en mayor medida su temperatura, con lo cual desciende su HR, mejorando su capacidad de secado. El espesor de 1.20 $\times 10^{-3} \mathrm{~m}$ además de llegar hasta valores de humedad menores, desciende de forma más rápida que el de 2.40 $x 10^{-3} \mathrm{~m}$. Sin embargo, el mayor espesor elimina una mayor cantidad de humedad en las $4 \mathrm{~h}$ de ensayo. Por lo que usar un mayor espesor genera mejor productividad en el proceso global.

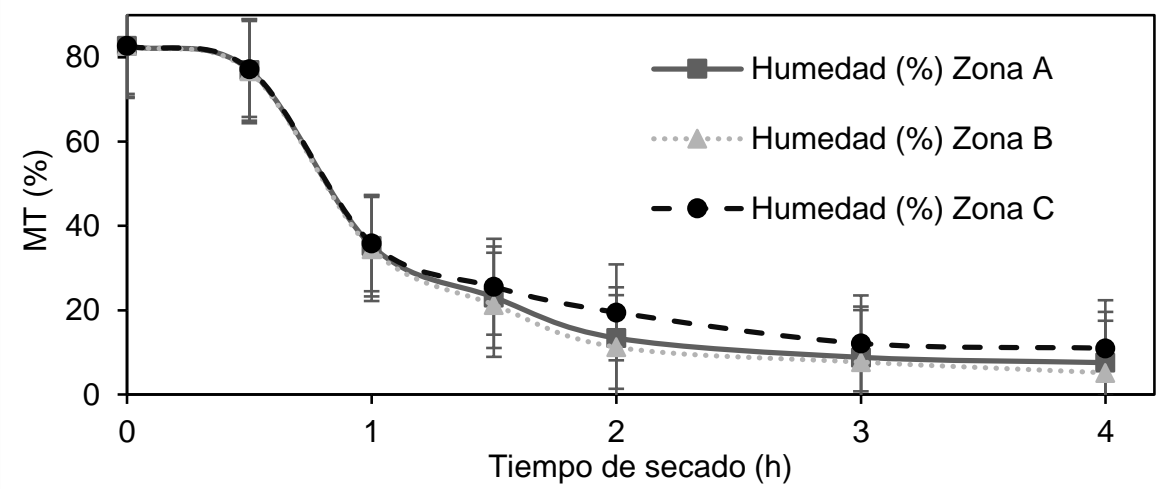

(A)

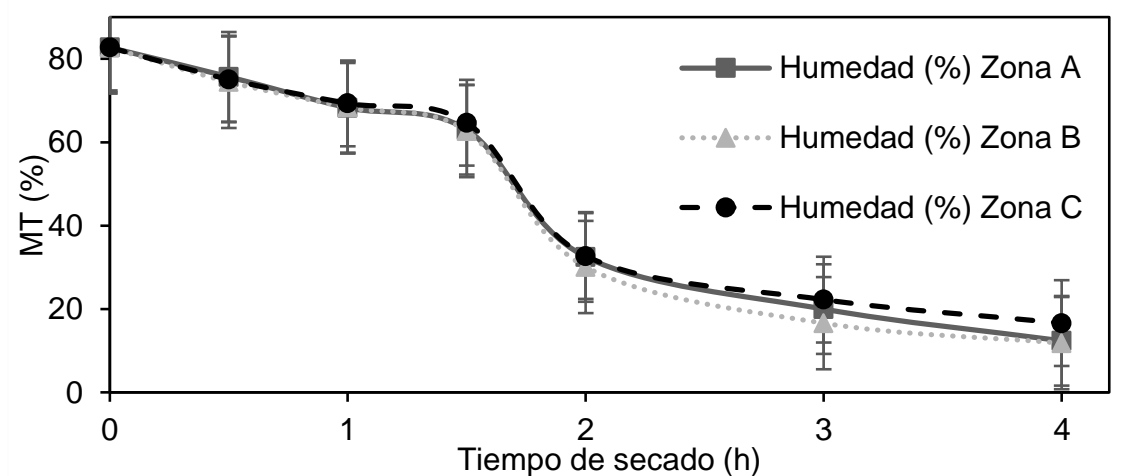

(B)

Fig. 4: Contenido de humedad vs tiempo con diferentes espesores de película de EQ durante el EXP1. (A) Colector CX. (B) Colector CY

En la figura 5 se presenta la velocidad de secado en función del contenido de humedad de EQ en el EXP1, en los colectores CX y CY, denominada curva de velocidad de secado (Badaoui et al., 2019). Se observa que el colector CX presenta alta velocidad de secado desde los primeros momentos, cuando el producto contiene aun valores de humedad altos, lo que se debe al hecho de que la masa de producto es baja con respecto al área de transferencia y el espesor mínimo $\left(1.20 \times 10^{-3} \mathrm{~m}\right)$, por lo que el producto se calienta rápidamente e 
inicia el proceso de secado casi inmediatamente después de ser puesto en el colector. La tasa de velocidad más alta se obtuvo en la zona B, seguida de $A$ y por último la C con valores máximos de $268.54 \mathrm{Kg} \mathrm{H} 2 \mathrm{O} / \mathrm{h} . \mathrm{m}^{2}$, $265.45 \mathrm{Kg} \mathrm{H} 2 \mathrm{O} / \mathrm{h} . \mathrm{m}^{2}$ y $263.27 \mathrm{Kg} \mathrm{H} 2 \mathrm{O} / \mathrm{h}^{2} \mathrm{~m}^{2}$ respectivamente. Por su parte en el colector $\mathrm{CY}$ al tener una película de EQ con mayor espesor $\left(2.40 \times 10^{-3} \mathrm{~m}\right)$, se genera primero una fase de calentamiento y adaptación, en la que el aire alcanza las condiciones de HR y temperatura necesarias para el secado convectivo en la cámara, mientras que la cama de secado (caja Petri) va aumentando su temperatura por efecto del calentamiento por conducción y radiación, hasta que el agua en su interior alcance las condiciones para el cambio de fase (Wang et al., 2018). En ambos colectores se observa la ausencia de la fase de velocidad constante, precisamente porque las condiciones del aire no son uniformes a lo largo de todo el proceso, pero es clara la presencia de la fase de velocidad decreciente como se obtuvo en estudios recientes en productos a partir de desechos de orujo de tomate y otros productos vegetales (Badaoui et al., 2019).

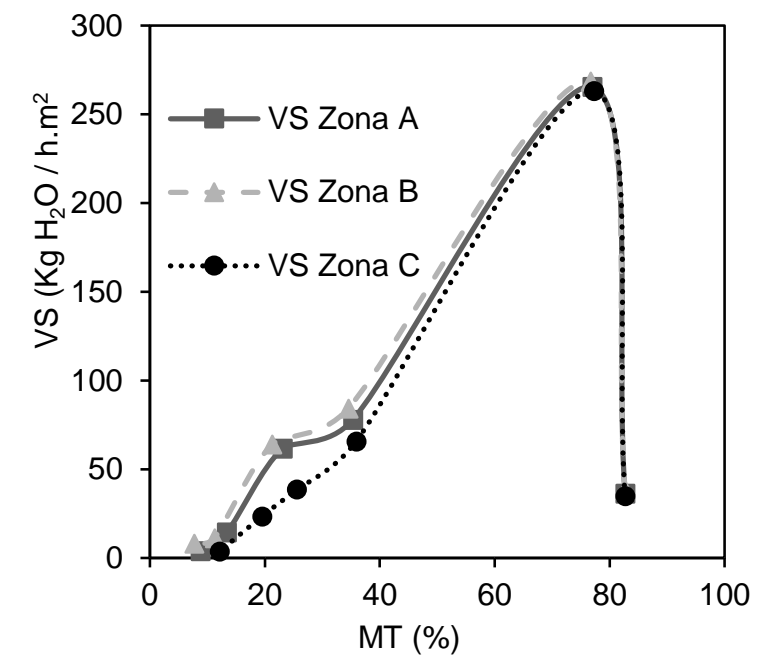

(A)

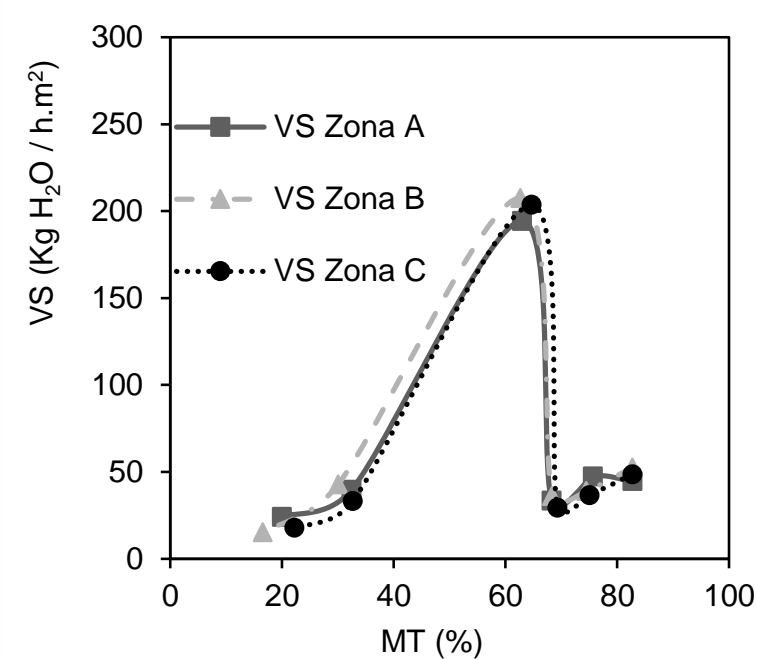

(B)

Fig. 5: Velocidad de secado bajo diferentes espesores de EQ durante el EXP1. (a) CX. (b) CY.

\section{Difusividad efectiva}

Los $D_{\text {ef }}$ fueron calculados con el modelo de la solución analítica de la segunda ley de Fick desarrollado por Crank en 1975 (ecuación 4) y se muestran en la tabla 4, donde se observa que en las 3 zonas y los dos espesores muestran $D_{\text {ef }}$ diferentes. Se observa que el colector CY presenta los mayores valores de $D_{\text {ef, }} a$ pesar de que en dicho colector no se obtiene el producto más deshidratado (tabla 2). Por otro lado, no se sigue un comportamiento similar en los colectores, pues el colector CX proporcionó el mayor $D_{\text {ef }}$ en la zona $A$, mientras el que $C Y$ lo muestra en la zona $B$, caso contrario que ocurre cuando se compara el menor valor de este coeficiente.

Tabla 4: Coeficiente de difusión efectivo en el proceso de secado de EQ. EXP1

\begin{tabular}{|l|c|c|}
\hline Colector & Zona & $\mathrm{D}_{\text {ef }}\left(\mathrm{m}^{2} / \mathrm{s}\right)$ \\
\hline \multirow{2}{*}{$\begin{array}{l}\text { CX: } 1.20 \times 10^{-3} \mathrm{~m} \text { de } \\
\text { espesor de película. EXP1 }\end{array}$} & $\mathrm{A}$ & $6.54 \times 10^{-10}$ \\
\cline { 2 - 3 } & $\mathrm{B}$ & $5.44 \times 10^{-10}$ \\
\hline \multirow{2}{*}{$\begin{array}{l}\text { CY: } 2.40 \times 10^{-3} \mathrm{~m} \text { de } \\
\text { espesor de película. EXP1 }\end{array}$} & $\mathrm{C}$ & $5.54 \times 10^{-11}$ \\
\cline { 2 - 3 } & $\mathrm{A}$ & $2.11 \times 10^{-9}$ \\
\cline { 2 - 3 } & $\mathrm{C}$ & $2.15 \times 10^{-9}$ \\
\hline
\end{tabular}

De este modo, se determinó que el espesor de $2.40 \times 10^{-3} \mathrm{~m}$ es el que genera las mejores condiciones para el secado debido a que presenta la mayor productividad y más altos valores de $D_{\text {ef. }}$ Además, a pesar que no hay una clara coincidencia con los dos colectores en cuanto a la zona que presenta los mayores valores de $D_{\text {ef, }}$ pero se evidencia que las zonas A y B corresponden a las mejores zonas para el secado de EQ puesto que llegan a humedades necesarias para garantizar la estabilidad del producto $(<12 \%)$, mientras que la zona $\mathrm{C}$ a pesar de tener $D_{\text {ef }}$ muy similares a la zona $A$ y $B$, no logra llega a dicha humedad. Por esta razón se seleccionaron las zonas A y B del colector CY $\left(2.40 \times 10^{-3} \mathrm{~m}\right)$, para modelar las cinéticas de secado y monitorear termohigrométricamente el interior del colector, durante el proceso de secado, en el experimento siguiente (EXP2). 


\section{Modelamiento de la cinética de secado EXP2}

En este experimento se registraron los datos del aire atmosférico y del interior del colector, así como la humedad del producto en función del tiempo, los cuales fueron utilizados para modelar la cinética de secado.

\section{Monitoreo de las condiciones del aire y del producto durante el secado}

Al igual que el EXP1, el registro de los datos comenzó desde las 8:30 am y terminaron a las 12:30 pm, con el fin de mantener un tiempo de secado de 4 horas. Las diferencias con el EXP1 se dieron en cuanto a la disposición de producto a secar de acuerdo a los hallazgos encontrados, se eligieron las zonas A y B con muestras de ensilado de $2.40 \times 10^{-3} \mathrm{~m}$ de espesor de película. Las variaciones climáticas se ilustran en la figura 6 , donde se observa que la temperatura incrementa con la radiación, mientras que la HR es inversa a la misma. El valor máximo se registró a las 9:32 am y el valor mínimo en la primera hora una vez iniciado el experimento. La temperatura ambiente se mantuvo entre 35.50 y $45.80^{\circ} \mathrm{C}$, mientras que a humedad relativa estuvo entre 23.30 y $45.90 \%$.

En la figura 7 se presenta el comportamiento de temperatura en el interior del colector $C Y$ en función del tiempo. Se evidencia que las zonas A y B alcanzan los mayores valores de temperatura, a pesar de contener producto húmedo, que hace que la temperatura descienda. Las más altas temperaturas se obtienen en la zona $\mathrm{B}$, con valores entre 31.70 a $92.90^{\circ} \mathrm{C}$, manteniéndose por encima de $80^{\circ} \mathrm{C}$ por más de $2 \mathrm{~h}$, lo cual se puede deber a la baja carga del colector y a la ausencia de material en la zona C. Esto pone de manifiesto que la trayectoria recorrida por el aire al interior del colector es lo que hace posible que su temperatura se incremente. Al llegar a la zona B, el aire empieza a extraer agua del producto, por lo que al pasar a la zona A, se observa como su humedad relativa se ha incrementado y su temperatura ha disminuido (Fig. 7), por lo que en la zona A (humedad final $10.69 \%$ ) el producto pierde menos humedad que en la zona B (humedad final $9.53 \%$ ), esto se observa en la figura 8.

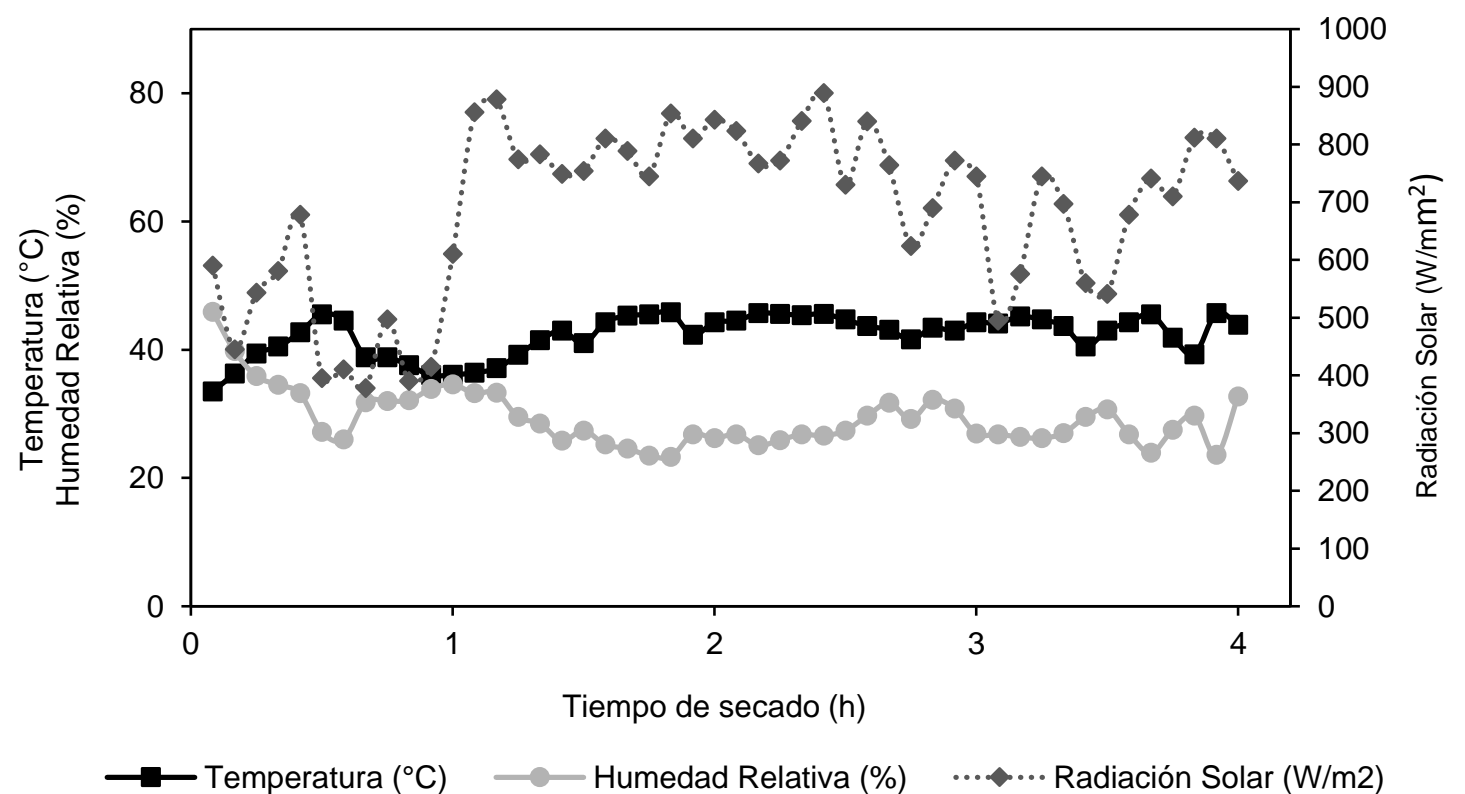

Fig. 6: Variación de las condiciones climaticas en el EXP2. Radiació solar, temperatura y humedad relativa en función del tiempo de secado.

En la figura 9 se aprecia el comportamiento de la velocidad de secado vs el contenido de humedad de las muestras de EQ para el colector CY en el EXP2, se ve que hay un punto máximo marcado en ambas zonas y luego el proceso es similar, ese punto generalmente es cuando se deja de disponer de agua en estado líquido en la superficie del producto. También se evidencia la ausencia de la fase de calentamiento, pero se observa la fase de velocidad constante, con valores máximos de $108.43 \mathrm{Kg} \mathrm{H} 2 \mathrm{O} / \mathrm{h} . \mathrm{m}^{2}$ y $123.63 \mathrm{Kg} \mathrm{H} 2 \mathrm{O}$ / h. $\mathrm{m}^{2}$ para la zona $\mathrm{A}$ y $\mathrm{B}$ respectivamente.

\section{Modelado empírico}

El modelo logarítmico, el de Henderson y Pabis y el de Verma, mostraron los valores de $\mathrm{R}^{2}$ más bajos 0.93 , 0.93 y 0.98 respectivamente, mientras que los de Page, Midilli, Danish fueron mayores de 0.995. 


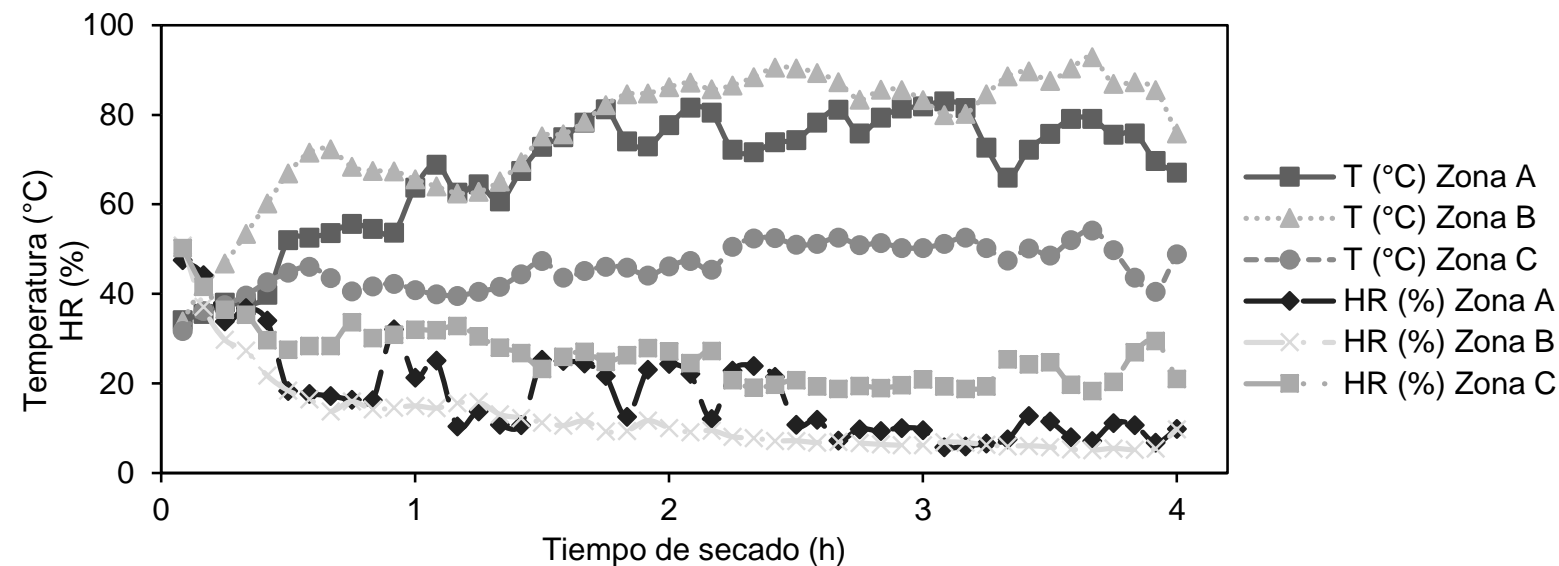

Fig. 7: Variación de la temperatura interna con respecto al tiempo en las diferentes zonas del colector CY en el EXP2.

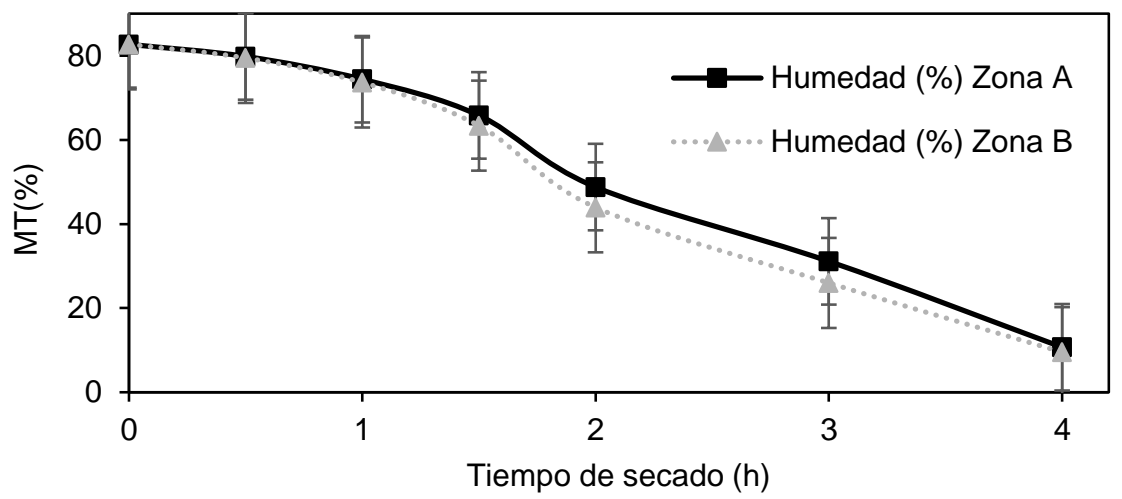

Fig. 8: Contenido de humedad vs tiempo del colector CY en el EXP2

Del mismo modo, al analizar los otros parámetros estadísticos como el MAE $(<0.03)$, RMSE $(<0.04)$ y $X^{2}$ $(<0.002)$ se observa que los valores más bajos los obtuvo el modelo de Page seguido del modelo de Midilli y Danish con parámetros similares para la zona A y la zona B en cada modelo mostrando el mejor ajuste. Por lo tanto, estos son los modelos seleccionados para describir el comportamiento del secado solar de capa delgada de EQ. Estos resultados concuerdan con los de Badaoui et al., 2019, quienes obtuvieron los mejores ajustes con el modelo de Midilli, en un estudio experimental de secado de desechos de orujo de tomate en un invernadero solar. Así mismo Essalhi et al., 2018, con este mismo modelo obtuvieron el mejor ajuste en el secado solar de uvas bajo un secador solar indirecto y al sol abierto. En la figura 10 se observan los datos experimentales y predichos de MR con respecto al tiempo de secado, ajustados con los modelos de Page y Midilli, lo que corrobora el excelente ajuste obtenido para estos modelos que se presentaron en la tabla 5.

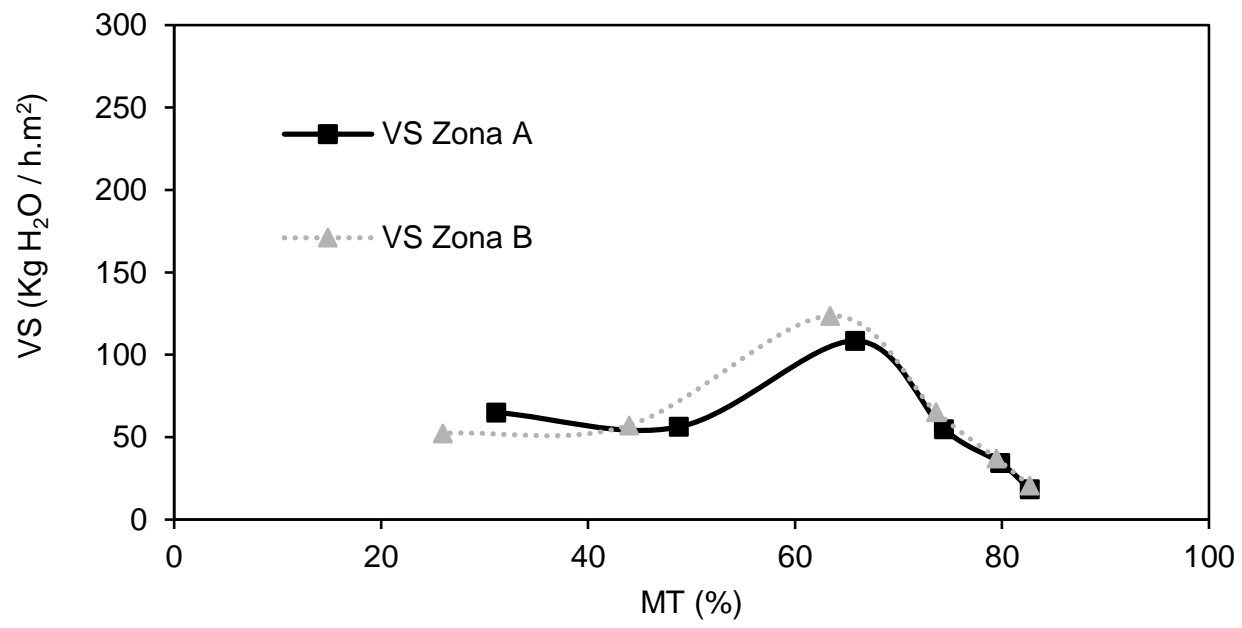

Fig. 9: Velocidad de secado de EQ durante el EXP2 


\section{Modelamiento fenomenológico}

Los $D_{\text {ef }}$ fueron calculados del mismo modo que en el EXP1, pero solo para las zonas seleccionadas (A y B). En la tabla 6 se muestran los valores de $D_{\text {ef }}$ calculados, así como los parámetros estadísticos asociados a la bondad de ajuste. Se observa que el $\mathrm{D}_{\text {ef }}$ de la zona $\mathrm{B}$ fue el mayor, conservando un comportamiento similar al obtenido en el EXP1. Este comportamiento se explica con base en los valores de temperatura del aire en el interior del colector, puesto que la zona de mayor temperatura promedio fue justamente la zona $\mathrm{B}$, gracias al efecto que esta variable tiene sobre el $D_{\text {ef }}$ (Wang et al., 2018; Badaoui et al., 2019).

Tabla 5: Resultados obtenidos de los parámetros de los modelos de capa delgada aplicados en el proceso de secado solar de EQ de $2.4 \times 10^{-3} \mathrm{~m}$ de espesor en la zona A y B. EXP2.

\begin{tabular}{|c|c|c|c|c|c|c|}
\hline Modelo & $\begin{array}{l}\text { Configuración } \\
\text { Experimental } 2\end{array}$ & Coeficientes del modelo & $R^{2}$ & $M A E$ & $R M S E$ & $x^{2}$ \\
\hline \multirow{2}{*}{ Page } & Zona A & $k=0.1156 ; n=2.3089$ & 0.9955 & 0.0270 & 0.0339 & 0.0013 \\
\hline & Zona B & $k=0.1368 ; n=2.2866$ & 0.9968 & 0.0242 & 0.0292 & 0.0010 \\
\hline \multirow{2}{*}{ Midilli } & Zona A & $k=0.1089 ; n=2.3576 ; a=0.9901 ; b=0.007$ & 0.9956 & 0.0269 & 0.0336 & 0.0013 \\
\hline & Zona B & $k=0.0904 ; n=2.8477 ; a=0.9796 ; b=0.0066$ & 0.9936 & 0.0343 & 0.0415 & 0.0020 \\
\hline \multirow{2}{*}{ Danish } & Zona A & $k=0.1156 ; n=2.3089 ; b=0.0001$ & 0.9951 & 0.0279 & 0.0345 & 0.0018 \\
\hline & Zona B & $k=0.1368 ; n=2.2866 ; b=0.0001$ & 0.9962 & 0.0247 & 0.0297 & 0.0015 \\
\hline \multirow{2}{*}{ Logaritmica } & Zona A & $k=0.4017 ; a=1.350 ; c=0.0001$ & 0.9377 & 0.1058 & 0.1260 & 0.0185 \\
\hline & Zona B & $\mathrm{K}=0.4327 ; \mathrm{a}=1.1357 ; \mathrm{c}=0.0002$ & 0.9320 & 0.1075 & 0.1240 & 0.0179 \\
\hline \multirow{2}{*}{$\begin{array}{l}\text { Henderson y } \\
\text { pabis }\end{array}$} & Zona A & $k=0.4017 ; a=1.350 ; c=0.000$ & 0.9378 & 0.1058 & 0.1260 & 0.0185 \\
\hline & Zona B & $\mathrm{K}=0.4327 ; \mathrm{a}=1.1357 ; \mathrm{c}=0.000$ & 0.9321 & 0.1074 & 0.1239 & 0.0178 \\
\hline \multirow{2}{*}{ Verma } & Zona A & $\mathrm{k}=0.8487 ; \mathrm{a}=4.8805 ; \mathrm{g}=1.1678$ & 0.9861 & 0.0428 & 0.0617 & 0.0044 \\
\hline & Zona B & $\mathrm{k}=0.9045 ; \mathrm{a}=4.9532 ; \mathrm{g}=1.2368$ & 0.9894 & 0.0404 & 0.0560 & 0.0037 \\
\hline
\end{tabular}

Tabla 6. Resultados obtenidos de los parámetros del modelo fenomenológico aplicados en el proceso de secado solar de EQ de $2.40 \times 10^{-3} \mathrm{~m}$ de espesor en la zona A y B. EXP2

\begin{tabular}{|c|c|c|c|c|c|c|}
\hline Colector & Configuración EXP2 & $D_{\text {ef }}\left(\mathrm{m}^{2} / \mathrm{s}\right)$ & $R^{2}$ & $M A E$ & $R M S E$ & $X^{2}$ \\
\hline \multirow{2}{*}{$\mathrm{cY}$} & Zona A & $2.04 \times 10^{-9}$ & 0.5197 & 0.4638 & 0.5713 & 0.3808 \\
\cline { 2 - 7 } & Zona B & $3.06 \times 10^{-9}$ & 0.5368 & 0.4416 & 0.5526 & 0.3562 \\
\hline
\end{tabular}

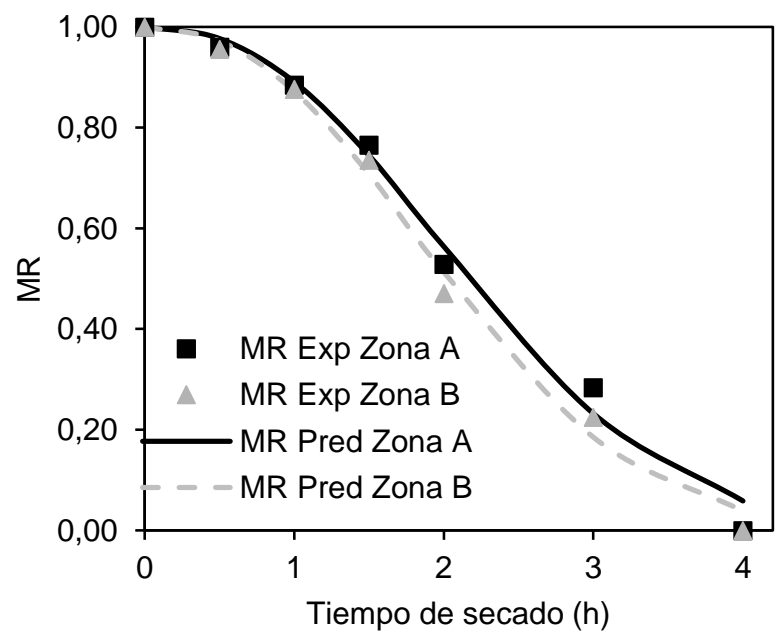

(A)

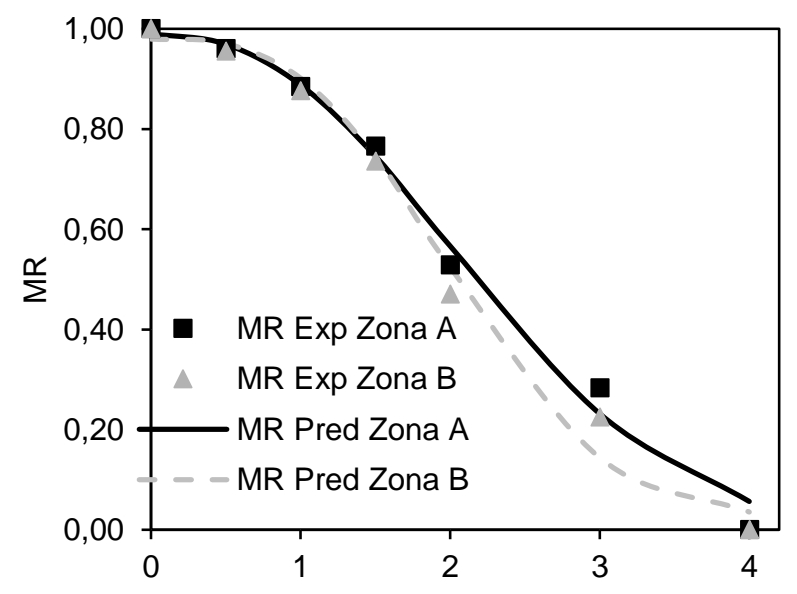

(B)

Fig. 10: Comparación entre los valores experimentales y predichos de la MR con los 2 modelos empíricos de mayor ajuste y modelo fenomenológico para $L=2.40 \times 10^{-3} \mathrm{~m}$. (A) Page. (B) Midilli. 
Al comparar los valores de bondad de ajuste, así como el comportamiento gráfico de los valores experimentales vs los predichos, para los modelos de Page, Midilli y el derivado de la solución de la ecuación de Fick, es claro que el mejor ajuste lo entregan los modelos empíricos, sin embargo se debe tener en cuenta que estos modelos no permiten profundizar en el entendimiento fenomenológico del proceso, mientras que el de Fick, por ser de base fenomenológica permite una extrapolar resultados y escalar procesos. De todas formas, el excelente ajuste obtenido por los modelos empíricos permite apreciar la aplicación de estos modelos en este tipo de procesos y ofrece información valiosa para quien pretenda utilizar las condiciones establecidas en este trabajo, para desarrollos futuros.

\section{CONCLUSIONES}

De los resultados mostrados, de su análisis y de su discusión, se pueden obtener las siguientes conclusiones, sobre el proceso de secado solar de EQ en un secador solar directo con efecto pasivo. 1) El espesor de película del EQ, así como la ubicación dentro del secador, tienen efecto significativo sobre las características del ES y sobre la cinética del proceso de secado. 2) El ES obtenido bajos las condiciones del presente estudio tiene características bromatológicas y microbiológicas, que le permiten ser utilizado en la alimentación de diferentes especies animales. 3) La cinética de secado del EQ se puede modelar por medio de ecuaciones empíricas como la de Page, Midilli y Danish, así como por fenomenológicas como derivada por la ecuación de Fick para placas planas.

\section{AGRADECIMIENTOS}

Los autores del presente trabajo dan las gracias a la Universidad de Antioquia y a COLCIENCIAS (proyecto 58746) por el apoyo financiero brindado para su desarrollo.

\section{NOTACIONES}

\section{Símbolos}

$D_{\text {ef }}=$ Coeficiente de Difusividad efectiva

$\mathrm{MAE}=$ Error absoluto medio

$\mathrm{MD}=$ Materia seca de muestra de ensilado químico

$\mathrm{M}_{\mathrm{e}}=$ Humedad en equilibrio

$\mathrm{MH}=$ Masa de ensilado químico en tiempo $\mathrm{t}$

$\mathrm{NMP}=$ número más probable

$\mathrm{MR}=$ Relación de humedad

$M_{0}=$ Humedad inicial

MT = Cantidad de humedad en un tiempo t

$R^{2}=$ Coeficiente de correlación

RMSE $=$ Error cuadrático medio

$\mathrm{UFC} / \mathrm{g}=$ Unidades formadoras de colonia por gramo

$\mathrm{VS}=$ Velocidad de secado

$X^{2}=$ Chi-cuadrado reducido

\section{Abreviaciones}

$\mathrm{CX}=$ Colector con capas de ensilado químico de $1.20 \times 10^{-3} \mathrm{~m}$ de espesor de película

$\mathrm{CY}=$ Colector con capas de ensilado químico de $2.40 \times 10^{-3} \mathrm{~m}$ de espesor de película

$\mathrm{EF}=$ Ensilado químico fresco

$\mathrm{EQ}=$ Ensilado químico

$\mathrm{ES}=$ Ensilado químico seco

EXP1= Experimento 1

EXP2= Experimento 2

$\mathrm{PMMA}=$ Polimetilmetacrilato

\section{REFERENCIAS}

Akpinar, E. K., Mathematical Modelling of Thin Layer Drying Process Under Open Sun of Some Aromatic Plants, doi:10.1016/J.Jfoodeng.2005.08.014, Journal of Food Engineering, 77(4), 864-870 (2006).

AOAC, Official Methods Of Analysis Of AOAC International, 17 ${ }^{\mathrm{a}}$ Ed., 2-66. Association of Official Analysis Chemists International, Washington, USA (2000).

Badaoui, O., S. Hanini y otros tres autores, Experimental And Modeling Study Of Tomato Pomace Waste Drying In A New Solar Greenhouse: Evaluation Of New Drying Models, doi:10.1016/J.Renene.2018.10.020, Renewable Energy, 133, 144155 (2019).

Baher, M., G. Klaus y M.A. Hossain, Integrated hybrid solar drying system and its drying kinetics of chamomile, doi:10.1016/j.renene.2018.01.055, Renewable Energy, 121, 539-547 (2018).

Crank, J., The Mathematics Of Diffusion, $2^{\mathrm{a}}$ Ed., Clarendon Press, Bristol, Inglaterra (1975). 
Danish, M., H. Jing y otros tres autores, A New Drying Kinetic Model for Sewage Sludge Drying in Presence of Cao and Naclo, doi:10.1016/J.Applthermaleng.2016.05.191, Applied Thermal Engineering, 106(1), 141-152 (2016).

Essalhi, H., M. Benchrifa y otros dos autores, Experimental and Theoretical Analysis of Drying Grapes Under an Indirect Solar Dryer and in Open Sun, doi:10.1016/J.Ifset.2018.08.002, Innovative Food Science And Emerging Technologies, 49, 58-64 (2018).

Gabas, A.L., J. Telis-Romero y otros dos autores. Propiedades termodinámicas de sorción de agua de la pulpa de lulo en polvo con encapsulantes, ISSN: 0101-2061. Ciênc. Tecnol. Aliment, 29(4), 911-918 (2009).

Gallardo, P., G. Gaxiola y otros cinco autores, Nutritive Value of Diets Containing Fish Silage for Juvenile Litopenaeus Vannamei, doi:10.1002/Jsfa.5632, Journal of The Science of Food and Agriculture, 92(11), 2320-2325 (2012).

Goddard, J. S. y J. S. Perret, Co-Drying Fish Silage for Use in Aquafeeds, doi:10.1016/J.Anifeedsci.2004.11.004 Animal Feed Science and Technology, 118(3-4), 337-342 (2005).

Goosen, N. J., L.F. De Wet y J.F. Görgens, Rainbow Trout Silage as Immune Stimulant and Feed Ingredient in Diets for Mozambique Tilapia (Oreochromis Mossambicus), doi:10.1111/Are.12497, Aquaculture Research, 47(1), 329-340 (2016).

Hamdi, I., S. Kooli y otros tres autores, Experimental Study and Numerical Modeling for Drying Grapes Under Solar Greenhouse, doi: 10.1016/J.Renene.2018.05.027, Renewable Energy, 127, 936-946 (2018).

Hincapié, M.A. y J.E. Zapata. Estudio de la Cinética de Deshidratación de Uchuva (Physalis peruviana L) en un Secador de Lecho Fluidizado, doi:10.4067/S0718-07642019000200115, Inf. Tecnol. 30(2), 115-124 (2019).

Karthikeyan, A. K. y S. Murugavelh, Thin Layer Drying Kinetics and Exergy Analysis of Turmeric (Curcuma Longa) in A Mixed Mode Forced Convection Solar Tunnel Dryer,doi:10.1016/J.Renene.2018.05.061, Renewable Energy, 128, 305312 (2018).

Madage, S.S.K., W.U.D. Medis e Y. Sultanbawa, Fish Silage as Replacement of Fishmeal in Red Tilapia Feeds, doi: 10.1080/10454438.2015.1005483, Journal of Applied Aquaculture, 27(2), 95-106 (2015).

Majumdar, R. K., S. Deb y K. Nath, Effect of Co-Dried Silage From Fish Market Waste as Substitute for Fish Meal on the Growth of the Indian Major Carp Labeo Rohita Fingerlings, Indian Journal Fish., 61(4), 63-68 (2014).

Martínez-Alvarez, O., S. Chamorro y A. Brenes. Protein Hydrolysates from Animal Processing By-Products as a Source of Bioactive Molecules With Interest in Animal Feeding: A Review, doi:10.1016/J.Foodres.2015.04.005, Food Research International, 73(1069), 204-212 (2015).

Minh, N. P., Effect of Water Temperature and Time During Tilapia Processing to its Fillet Quality, ISSN: 2349-4182, International Journal of Multidisciplinexary Research and Development, 1(6), 178-184 (2014).

Nørgaard, J. V., K. Blaabjerg y H. Poulsen, Salmon Protein Hydrolysate as a Protein Source in Feed for Young Pigs, doi: 10.1016/J.Anifeedsci.2012.08.003, Animal Feed Science and Technology, 177(1-2), 124-129 (2012).

Olsen, R. L., J. Toppe e I. Karunasagar, Fish Silage Hydrolysates Not Only a Feed Nutrient, But Also a Useful Feed Additive, doi: 10.1016/j.tifs.2017.06.003 ,Trends Food Science Technology, 66, 93-97 (2017).

Puente, L.A., C.A. Pinto-Muñoz y otros dos autores, Physalis peruviana Linnaeus, the Multiple Properties of a Highly Functional Fruit: A Review, doi:10.1016/j.foodres.2010.09.034, Food Res. Int, 44(7), 1733-1740 (2011).

Qiu, J., K. Kloosterboer y otros tres autores, Conductive Thin Film Drying Kinetics Relevant to Drum Drying, doi: 10.1016/J.Jfoodeng.2018.08.021, Journal of Food Engineering, 242, 68-75 (2018)

Rodríguez-González, H., M. López-Aguilar y otros tres Autores. Use of A Mixture of Vegetal (Jatropha Curcas) and Animal (Fish Silage) Byproducts as Protein Source in Shrimp (Litopenaeus Vannamei) Diets, doi: 10.1590/Rbz4720170165, Revista Brasileira De Zootecnia, 47 (2018)

Saadi, S., N. Saari y otros tres autores, Recent Advances In Food Biopeptides: Production, Biological Functionalities and Therapeutic Applications, doi:10.1016/J.Biotechadv.2014.12.003, Biotechnology Advances, 33(1), 80-116 (2015).

Sagada, G., C. Jianming y otros cinco autores, Optimizing Protein and Lipid Levels in Practical Diet for Juvenile Northern Snakehead Fish (Channa Argus), doi:10.1016/J.Aninu.2017.03.003, Animal Nutrition 3(2), 156-6 (2017).

Santana-Delgado, H., E. Avila y A. Sotelo, Preparation of Silage from Spanish Mackerel (Scomberomorus Maculatus) And Its Evaluation In Broiler Diets, doi:10.1016/J.Aninu.2017.03.003, Animal Feed Science and Technology, 141(1-2), 129140 (2008).

Sharma, A., C.R. Chen y N. Vu Lan, Solar-Energy Drying Systems: A Review, doi:10.1016/J.Rser.2008.08.015, Renewable and Sustainable Energy Reviews, 13(6-7), 1185-1210 (2009).

Van 'T Land, M., E. Vanderperren y K. Raes, The Effect of Raw Material Combination on the Nutritional Composition and Stability of Four Types of Autolyzed Fish Silage, doi:10.1016/J.Anifeedsci.2017.10.009, Animal Feed Science and Technology, 234, 284-294 (2017).

Wang, P., D. Mohammed, y otros cuatro autores, Q. Roof Solar Drying Processes for Sewage Sludge Within SandwichLike Chamber Bed, doi: 10.1016/J.Renene.2018.09.081, Renewable Energy, 136(C), 1071-1081 (2018).

Zhand, Q. y J.B. Litchfield, An Optimization of Intermittent Corn Drying In A Laboratory Scale Thin Layer Driyer, doi:10.1080/07373939708917254, Drying Technology, 9(2), 37-41 (1991). 